\title{
SCENJUDEN SHYLOCK OCH HANS ARVINGAR
}

\author{
Karmela Bélinki \\ Helsingfors
}

Vem var Shylock och var han någon alls, kan verka vara en långsökt fråga. Likväl är det ett lika obesvarat spörsmål som vem handskmakarens son var och om han var någon alls. Både handskmakarens son - med eller utan citationstecken - och hans kreation Shylock har varit banbry tare inom samma fack. Om fadern inget ont, skapelsen kan man diskutera.

Vad visste tudortidens engelska artister om judar? De visste vad de hade hört och läst, men om de inte hade rest pa kontinenten hade de knappast träffat en enda jude. Det sistnämnda har dock aldrig hindrat någon från att ha en förutbestämd - i allmänhet negativ - åsikt om judama. Inom parentes kan sägas att judarnas stat Israel fått ärva samma fenomen.

Det hade officiellt inte fått finnas judar i England sedan 1290 då de utvisades och visst hade väl en eller annan jude förirrat sig till England också efter det årtalet, speciellt under tiden kring digerdöden på 1300-talet då hundratusen judar förvisats från Frankrike efter att ha blivit beskyllda för att ha förgiftat de kristnas brunnar. Den jude som mot förmodan nått England hade inte blivit långvarig där. Han hade antingen bragts om livet eller utvisats. Sannolikt hade man inte väntat på myndigheterna.

Under hussitupproret hade judar beskyllts för att ha huggit huvudet av en kyrkvärds hustru och förlustat sig på hennes blod. Hos katolikerna var myten om judarnas ritualmord på kristna bam i samband med den judiska påsken seglivad. Judeoroligheterna utmynnade $\mathrm{i}$ inkvisitionen och autodaféerna där tusentals fick sätta livet till. Till sist förvisades hundratusen judar från Spanien 1492 samma år som Columbus ansatte sin resa till nya världen. ${ }^{1}$
Trots att få hänvisningar till dessa händelser finns i engelska annaler kan man anta att judarna var ett samtalsämne. Termen jude var sannolikt alltså en abstraktion i tudortidens litteratur utan realistisk eller empirisk grund.

Abstraktion eller ej, stereotypen, klichéföreställningen, schablonen existerade $\mathrm{i}$ litteraturen. I medeltida ballader omtalas den judiska penninghandlaren och kristusmördaren och också ritualmördaren skymtar $i$ en del av dem.

Scenjuden föddes med två typiska elisabetanska pjäser, Christopher Marlowes The Rich Jew of Malta (1592) och William Shakespeares The Merchant of Venice (Köpmannen från Venedig) (1597-1598). The Rich Jew of Malta kan tänkas ha haft flera levande modeller. Judamas exil från Spanien hade fördrivit flera betydande familjer till bl.a. Turkiet och i synnerhet familjen Nasi spelade en stor roll i politiken under 1500 talets senare hälft. Också en annan jude David Passi arbetade för turkiska politiska intressen på Malta under 1580-talet. Hur som helst är Marlowes Barabas en fröjd för alla anti-judiska känslor och en personifiering av all den ondska som judarna traditionellt behäftats med.

Barabas har två passioner, sin dotter och sitt kristna hat. En stilren elisabetansk komedi med all sköns förvecklingar och intriger innehåller som sidotema ett drama, så ock The Rich Jew of Malta. Barabas förlorar sina rikedomar och återvinner dem för att till slut gå under efter att ha förrått både sina nya och gamla bundsförvanter. En stor del av Barabas repliker är så groteska att de skulle få senare tiders Stürmers och andra Völkische Beobachters att blekna:

1 Montagu Frank Modder: The Jew in The Literature of England. Meridian Books and The Jewish Publication Society of America, New York and Philadelphia 1960, ss. 1-16. 
"I am not the tribe of Levi, I.

That can so soon forget an injury.

We Jews can fawn like spaniels when they please:

And when we grin we bite; yet are our looks As innocent and harmless as lamb's." 2

The Rich Jew of Malta blev en enorm framgång och kanske inte minst därför beslöt Shakespeare upprepa samma tacksamma tema. Att slå den värnlösa har tillhört de främsta folknöjena i alla tider, och Shakespeare var i allra högsta grad en son av sin tid.

Det finns stora likheter mellan de båda judiska karaktärerna, både fysiskt och psykiskt. Med dem etablerades scenjuden som en svartmuskig höknäst, gestikulerande föraktlig figur, ondskan personifierad. Hans främlingskap styrks av att han talar landets språk med en främmande, icke definierbar accent, sk. scenjudiska (Bühnenjüdisch eller Jewish gibberish, icke att förväxla med jiddisch). Scenjuden är en ockrare vars största passion är att dra sina kristna kontrahenter vid näsan.

Judiska lagar och riter tolkas på ett för judarna ogynnsamt sătt som farliga fờ de kristna. Det är en seglivad vulgär mytifiering och mystifiering som man naturligtvis kan avfärda med okunskap om judiskt väsen, men som har betydligt djupare rötter och i själva verket kan tänkas gå tillbaka till Nya Testamentets protest mot det judiska. Shylock (Akt 1, scen 3):

"Joo! Känna oss av fläsk; förtära den boning, vari er profet, nazaréen, inkvarterade djävulen. Jag vill köpa och sälja med er, jag vill prata med er, spatsera med er, och så vidare. Men jag vill ej ăta med er, dricka med er, ej heller göra bön med er." (Hagbergs övers. rev. av Molin)

I framställningen av Shylock har en viss modifiering kunnat skönjas. Interpreter har försökt framhäva det patetiska och ömkansvärda i Shylocks karaktär och bl.a. har första avdelningen av Shylocks stora monolog i Akt III, scen 1 framförts som ett bevis på Shakespeares mera nyanserade poträtt av juden. I moderna scenver- sioner har den kommit att framstå som det ledande temat:

"Har icke en jude ogon? Har icke en jude
händer, lemmar, organ, sinnen, tycken, pas-
sioner? Lever han icke av samma föda,
såras han icke av samma vapen, hemsökes
han icke av samma akommor, botas han
icke med samma läkemedel, vämes han
icke och kyles av samma vinter och sommar
som en kristen? Om ni sticker oss, blöda vi
icke? Om ni kittlar oss, kikna vi icke? Om
ni förgiftar oss, dö vi icke? (Hagbergs
övers.)

Men sedan sker någonting $\mathrm{i}$ monologen som tvivelsutan förtar den avväpnande effekten. Shylock är och förblir den ondskefulla och dvävulska figur som han alla senare tiders tolkningar till trots är avsedd att vara. Här finns också en häpnadsväckande likhet med The Rich Jew of Malta:

"Om ni förolämpar oss, skola vi icke hämnas? Om vi likna er i allt det andra, så likna vi er i det ock. Om en jude förolämpar en kristen, vad är den kristna ödmjukheten? Hämnd. Om en kristen förolämpar en jude, vad bör hans fördragsamhet vara efter kristligt exempel? Hämnd, naturligtvis. Den elakhet, ni lärt mig, vill jag utöva, och det skulle vara illa bevänt, om jag icke skulle överträffa min lärare." (Hagbergs övers.)

Hämndbegäret kan ses som en direkt följd av judarnas påstådda brist på grundetik och av deras fanatiska framhävande av öga för öga, tand för tand principen i motsats till kristendomens kärleksbud.

Barabas satte ut spåret, Shylock breddade vägen - och sedan? Mera av samma vara, också i andra länders litteratur. Romanjuden var en variation av scenjuden och av scenjuden fanns det ännu färre variationer än av romanjuden. Tills vi kommer till Gotthold Ephraim Lessing och hans Nathan der Weise anno 1779. ${ }^{3}$

Egentligen är personkonstellationen i Nathan den vise densamma som i Köpmannen. Det handlar om den rike juden Nathan (i Jerusalem

Se Modder, op. cit, ss. 22-28. Om Lessings judiska källor se Wilfried Bamer: Vorurteil, Empirie, Rettung. Der junge Lessing und die Juden i Herbert A. Strauss und Christian Hoffmann (herausg.): Juden und Judentum in der Literatur. Deutscher Taschenbuch Verlag, München 1985, ss. 62-78. 
denna gång), sultanen Saladin, om Recha Nathans adoptivdotter och en ung tempelherre. Med finns också Daja, en kristen i Nathans hus, en dervisch och patriarken av Jerusalem och andra, både muslimer och kristna.

Också i denna pjäs beskylls juden Nathan för elakt uppsåt, för att ha hemliggjort sin protegées kristna härkomst. Men här råder den stora skillnaden. I stället för att ta för givet att juden har felat ifrågasätts förtalet och det kommer fram att Nathan räddat barnet från en säker död. Akt III, scen X:

"Tempelherren: Den vise, gode Nathan? Vad? - Han skulle ha understått sig att förfalska Naturens röst på ett sådant sätt? Att leda åt sidan så ett hjärtas ström, som skulle helt andra vägar ta på egen hand? -" (Gunnar Klintbergs övers.)

Det hela slutar med att Nathan för sultanen yppar att tempelherren och Nathans adoptivdotter är syskon och bam till sultanens bror. Som den i sanning rättfärdiga framstår juden Nathan.

Lessings Nathan är en litteraturhistorisk raritet, en heroisk jude. Han saknar scenjudens karakteristika. Han talar högtyska på scenen, han är naturligt stolt över sin härkomst och han är framför allt en rättskaffens människa. Han saknar förebilder i litteraturen - och tyvärr också efterföljare. Den typiska scenjuden var och förblev Shylock-typen, inte Nathan der Weise-avbilden.

Vi förflyttar oss etthundrafemtio år framåt i tiden, till det unga självständiga Finland och dess heroiska scengestalter. Sam Sihvo skrev sin pjäs Jägarens brud på 1920-talet, då jägarromantiken tog över wieneroperetternas husarfantasier. Till uppbyggnaden är Jägarens brud ett typiskt sångspel med sång- och dansnummer mellan dialogen. Till stilen är den en "borgerligare" variant av flottarpjäserna och farserna, en litteraturhistorisk kuriositet.

Dess persongalleri motsvarar genren. Hjältarna är finska jägare vid garnisonen i Libau som i väntan på sin hemresa dödar tiden i finsknationell anda med att supa och jaga kvinnor.

Intriger uppstår kring dem, Libau befinner sig mitt emellan det tyska och ryska politiska spelet. Pjäsen har en klar tendens, dvs. de finsktyska sympatiema med udden riktad mot ryssarna, trots att finnarnas självständighetssträvan hela tiden framhävs i enlighet med tidens anda. ${ }^{4}$

En av karaktärema i skådespelet är en annan raritet $i$ den finska litteraturen, juden Isak. Han har en rätt viktig biroll, han är språkrör, dvs. spion mellan de olika lägren. Isak är en obehaglig, suspekt och etiskt dubiös person. Han är den finska varianten av Shylock-typen, the stage Jew, der Bühnenjude. Hans stereotypa drag sticker fram trots att alla personer i pjäsen är starkt karikerade.

Intressanta är vissa kontraster som framhålls i pjäsen visavis Isak och de finska hjältama. Isak är kosmopolit, han talar finska med den odefinierbara judiska accenten och för pengar arbetar han för vem som helst över frontlinjerna. Han är den typiska vandrande juden i konflikt med den gedigna finska nationalhedern. T.o.m. antihjälten, den försupna savolaxiska subretten, förädlas av samma känsla för det finska fosterlandet. Anspelningar på herrefolkstänkandet finns också i övrigt i pjäsen. Hjälten Martti förälskar sig i en ung dansös Sabrina, som stilenligt är livländska, dvs. en hederlig finskugrisk tös. Mot all denna Blut und Boden-romantik ter sig Isaks vandrande juden-syndrom ännu groteskare och ännu mera antisemitisk.

Utan närmare efterforskning är det svårt att med säkerhet säga var Sihvo fått modellen för sin Isak. Knappast har han medvetet tänkt på Shylock, troligare är att stereotypen kommit in i hans pjäs med tyska förebilder. Antisemitiska skrifter torde det inte ha saknats.

Från det elisabetanska England till självständighetstidens Finland vandrar den arma Shylock i olika varianter, ständigt höknäst, babblande sin halvt om halvt obegripliga jargong, utan hemortskänsla eller hedersbegrepp, skymfande sina skymfare, med penningens makt som sitt enda rättesnöre. Någon vis Nathan förmådde inte bry ta av traditionen. Den lever vidare i den ryska folkmunnen idag och i arabisk propaganda. Inte heller de "neutrala" och de "kristna" går skottfria i denna dager. 